MILITARY TESHNICAL COLLEGE CAIRO - EGYIPT

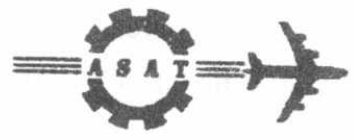

$7^{\text {th }}$ INTERNATIONAL CONF. ON AEROSPACE SCIENCES \& AVIATION TECHNOLOGY

\title{
ON THE ACCELERATION CONTROL OF DOUBLE SPOOL TURBOJET ENGINE OF UNKNOWN COMPRESSOR MAP
}

\author{
SHAFIEK, A. ${ }^{*}$ RABIE, M.G. ${ }^{* *}$ \& EL-ZAHABY A.A.**
}

\begin{abstract}
In this paper a method for theoretical prediction of double spool turbojet engine acceleration characteristics is presented. The acceleration characteristics of the engine are investigated on the basis of its compressors' maps with different operational limitations. Therefore, a special effort is paid for the construction of the studied engine compressors' maps. Different acceleration paths are selected on the compressor map and the required acceleration characteristics are calculated for each path. A non-linear model of the studied engine is developed and linearized about five different equilibrium points along the equilibrium run line. The linearized engine model is used to obtain the transient behavior of the engine. A special attention is paid to the effect of using the hydraulic retarder for acceleration control. The acceleration characteristics of the engine, equipped with hydraulic retarder, are determined by using a simulation program. The simulation program is used to predict the effect of the hydraulic retarder constructional parameters on the engine acceleration characteristics. These constructional parameters could be tuned to reproduce the required acceleration characteristivs of the engine.
\end{abstract}

\section{KEY WORDS}

Double spool, Turbojet engines, Compressor map, Acceleration, Control, Hydraulic retarder

\section{NOMENCLATURE}

$\begin{array}{lll}A_{p}: & \text { Piston front area, }\left(\mathrm{m}^{2}\right) \\ A_{n}: & \text { Exit nozzle area, }\left(\mathrm{m}^{2}\right) \\ A_{r}: & \text { Area of Restrictor, }\left(\mathrm{m}^{2}\right) . \\ B & \text { Fuel Bulk's modulus, }\left(\mathrm{N} / \mathrm{m}^{2}\right) . \\ C_{d}: & \text { Discharge coefficient through restrictor } \\ C_{p}: & \text { Specitic heat at constant pressure of air, }(\mathrm{J} / \mathrm{kgK})\end{array}$

* Researcher, Egyptian Air Force Research Center

** Professors, Chair of Aircraft Mechanics, Military Technical College 
$\mathrm{C}_{p} \quad$ : $\quad$ Specific heat at constant pressure of exhaust, $(\mathrm{J} / \mathrm{kgK})$.

f : Viscous friction coefficient, $(\mathrm{Ns} / \mathrm{m})$.

$\mathrm{G}_{\mathrm{f}} \quad$ : Fuel flow rate, $(\mathrm{kg} / \mathrm{s})$.

$J_{1} \quad$ High pressure rotor moment of inertia, $\left(\mathrm{Nms}^{2}\right)$.

$\mathrm{J}_{2} \quad$ : $\quad$ Low pressure rotor moment of inertia, $\left(\mathrm{Nms}^{2}\right)$.

$\mathrm{k}_{\text {eч }} \quad$ : Equivalent stiffness of the gate valve spring and piston.spring, $(\mathrm{N} / \mathrm{m})$

K : Adiabatic exponent of air.

$\mathrm{K}^{\prime} \quad$ : Adiabatic exponent of exhaust.

$\mathrm{L}_{\text {ad }}$ : Adiabatic work of shaft, $(\mathrm{J})$.

L. : Rotor shaft work, ( J ).

m : Fluid (Air \& Exhaust gases) mass flow rate, $(\mathrm{kg} / \mathrm{s})$.

$\mathrm{m}_{\mathrm{rd}} \quad$ : Reduced mass of piston rod, gate valve and their springs, $(\mathrm{kg})$.

M : $\quad$ Rotor moment, (Nm).

$\mathrm{n}$. : High pressure rotor number of revolution, ( $\mathrm{rpm}$ ).

$\mathrm{n}_{2} \quad$ : Low pressure rotor number of revolution, (rpm).

Fuel pressure after restrictor, $\left(\mathrm{N} / \mathrm{m}^{2}\right)$.

Constant working pressure of fuel enter the hydraulic retarder, $\left(\mathrm{N} / \mathrm{m}^{2}\right)$.

Fluid (Air \& Exhaust gases) Pressure, $\left(\mathrm{N} / \mathrm{m}^{2}\right)$.

Fuel flow through restrictor, $\left(\mathrm{m}^{3} / \mathrm{s}\right)$.

Radius of orifice $\underline{a},(\mathrm{~m})$

Laplace operator.

time, (s).

Fluid (Air \& Exhaust gases) Temperature, (K).

Volume of the chamber after restrictor, $\left(\mathrm{m}^{3}\right)$.

Gate valve displacement, (m).

Piston rod displacement, (m).

Relative displacement between the gate valve and piston rod, (m)

Efficiency.

Fuel density, $\left(\mathrm{kg} / \mathrm{m}^{3}\right)$.

Total pressure loss factor in combustion chamber.

Acceleration time, ( $s$ ).

Temperature deference, (K)

pressure ratio.

\section{Subscripts}

$\begin{array}{lll}\mathrm{e} & \text { Total } \\ \text { cal } & \text { Calculated } \\ \mathrm{d} & : & \text { Design } \\ \text { est } & \text { Estimated } \\ \mathrm{k} 1 & : & \text { High pressure compressor } \\ \mathrm{k} 2 & \text { Low pressure compressor } \\ \mathrm{m} & : & \text { Mechanical }\end{array}$




$\begin{array}{ccl}\max & : & \text { Maximum } \\ \text { t1 } & : & \text { High pressure turbine } \\ \text { t2 } & : & \text { Low pressure turbine } \\ \mathrm{x} & : & \text { High pressure compressor entry } \\ \mathrm{y} & : & \text { High pressure turbine exit } \\ 0 & : & \text { Far upstream of the engine } \\ 1 & : & \text { Compressor face } \\ 2 & : & \text { Compressor exit } \\ 3 & : & \text { Turbine entry } \\ 4 & : & \text { Turbine exit } \\ 5 & : & \text { Nozzle exit } \\ \omega & : & \text { Restrictor } \omega \\ \text { i } & : & \text { Restrictor i } \\ \text { ii } & : & \text { Restrictor ii } \\ \text { iii } & : & \text { Restrictor iii }\end{array}$

Superscripts

Relative

\section{1- INTRODUCTION}

The determination of the gas turbine engine performance is an important task during the design phase, where the only available method is the theoretical one. Propulsive efficiency is probably the most important measure of an aircraft engine's performance. However, another important measure is the time required to accelerate the engine from one thrust level to another. Engine acceleration is one of the functions of the engine control system, and may be accomplished via open loop scheduling or closed loop control. The most difficult problem in the acceleration control of a turbine engine is the proper limitation of fuel flow to avoid compressor surge.

On early engines, the fuel control was a simple "stop-cock" where the fuel flow was a direct function of the position of the pilot's throttle. On these engines, controlling fuel flow, to increase engine speed within imposed limits, was a task requiring considerable skill. Automatic acceleration devices permit rapid acceleration as possible within the given limitations without the pilot having to pay attention to the rate at which the throttle changes. If the engine state reaches the maximum permitted acceleration curve during acceleration, they act to reduce the fuel flow rate.

There have been considerable efforts in developing dynamic models of gas turbines. $D^{\prime} A z z O$ and Houpis, 1960 [1] discussed the traditional single input-single output and frequency domain methods. These traditional methods employed such tools as Nyquist diagrams, Bode plots, Root locus plots. They obtained a linearized transfer function representation of the engine in the vicinity of one or more operating points for the family of nonlinear equations describing the physical system to be controlled. Shiviakov, 1970 [2] developed a linear model of two shaft turbojet engine. The governing differential equations of the system are generally found to be nonlinear and can be linearized about an operating point. In the situations where the system is 
subjected to small perturbations, the linearized model can be used to synthesize stable linea: controllers. Sevich and beattie, 1974 [3] considered the minimization of acceleration time for turbojet engine, using fuel flow and exit nozzle area as control variables. They used a quadratic performance index to approximate minimum time solutions. However, they used a nonlinea: engine model, rather than a series of linear models. Zhang, et. al., 1990 [4] proposed dynamic model of a twin spool turbojet engine with two inputs and two outputs. With the aid of linear quadratic regulator theory, an optical regulator for a twin variable control system is designed. The resuits showed that, in the condition of a state perturbation on the system, the transient performance of the system recovered to original state is more satisfactory

In this paper, the required engine acceleration characteristics is accomplished by controlling the fuel flow using a hydraulic retarder which is an open loop automatic acceleration device which presents some time delay to insure that the operation of the engine during the acceleration process is in the allowable region.

\section{2- REGULATION METHODS OF THE STUDIED ENGINE}

For double spool turbojet engine with regulated exit nozzle, there are two regulating parameters ; fuel flow rate $G_{f}$ and exit nozzle area $A_{n}$. The possible ways of regulation in this case are given as follows:[5]

$$
\begin{array}{lll}
\text { 1- } G_{f} \text { controls } n_{1} ; & A_{n} \text { controls } n_{2} ; & T_{3 e} \text { or } T_{4 c} \text { is limited by } G_{f} \\
2-G_{f} \text { controls } n_{2} ; & A_{n} \text { controls } n_{1}, & T_{3 c} \text { or } T_{t_{c}} \text { is limited by } G_{f}
\end{array}
$$

The first distribution is more acceptable because the change of critical area of exit nozzle has a great influence on the low pressure rotor rotational speed $n_{2}$.

Figure 1 shows a block scheme of the regulation system of the studied engine which represent a system of two degree of freedom. The deviation of the speed $a_{1}$ from the required value could be corrected by controlling the fuel flow $G_{f}$ and the speed $n_{2}$ is regulated by controlling the exit nozzle area $A_{n}$, while the value of $T_{3}$, should be limited by the fuel flow $\mathrm{G}_{\mathrm{s}}$

\section{3- GAS TURBINE MODEL}

The model developed by Shiviakov [3] is that of a double spool turbojet engine, Fig. 2, where two compressors are connected to the turbine by concentric shafts. Considering the two shaft speeds and the temperatures in front of the high pressure turbine and after the low pressure turbine as outputs. The linearized model of the engine is obtained as follows (The equations describing the dynamics of the system are given in Appendix ):

$$
\begin{aligned}
& \left(a_{0} s^{2}+a_{1} s+a_{2}\right) \bar{n}_{1}=\left(b_{0} s+b_{1}\right) \bar{G}_{f}+\left(c_{0} s+c_{1}\right) \bar{A}_{n} \\
& \left(a_{0} s^{2}+a_{1} s+a_{2}\right) \bar{n}_{2}=\left(b_{2} s+b_{3}\right) \bar{G}_{\mathrm{f}}+\left(c_{2} s+c_{3}\right) \bar{A}_{n} \\
& \left(a_{0} s^{2}+a_{1} s+a_{2}\right) \bar{T}_{3_{5}}=\left(b_{1} s^{2}+b_{5} s+b_{6}\right) \bar{G}_{f}+\left(c_{4} s+c_{5}\right) \bar{A}_{n} \\
& \left(a_{0} s^{2}+a_{1} s+a_{2}\right) \bar{T}_{t_{c}}=\left(b_{5} s^{2}+b_{8} s+b_{9}\right) \bar{G}_{f}+\left(c_{6} s^{2}+c_{7} s+c_{8}\right) \bar{A}_{n}
\end{aligned}
$$


According to the law of regulation of the studied engine, the transient response of the jet engine could be described by the following transfer function, assuming constant surrounding conditions and fixed jet nozzle area.

$$
\frac{\overline{\mathrm{n}}_{1}}{\overline{\mathrm{G}}_{\mathrm{f}}}(\mathrm{s})=\frac{\mathrm{b}_{0} \mathrm{~s}+\mathrm{b}_{1}}{\mathrm{a}_{0} \mathrm{~s}^{2}+\mathrm{a}_{1} \mathrm{~s}+\mathrm{a}_{2}}
$$

This transfer function is valid only in the neighborhood of the steady state operating point; for small variations of $\bar{G}_{\mathrm{f}}$. The nonlinear system equations representing the studied engine were linearized about five different equilibrium points. The values of the coefficients of the transfer function have different values for different pre-selected steady state equilibrium points. These values are calculated from the engine thermal cycle and the high pressure compressor characteristics for $\overline{\mathrm{n}}_{1}=0.8,0.86,0.9,0.935,1.001$.

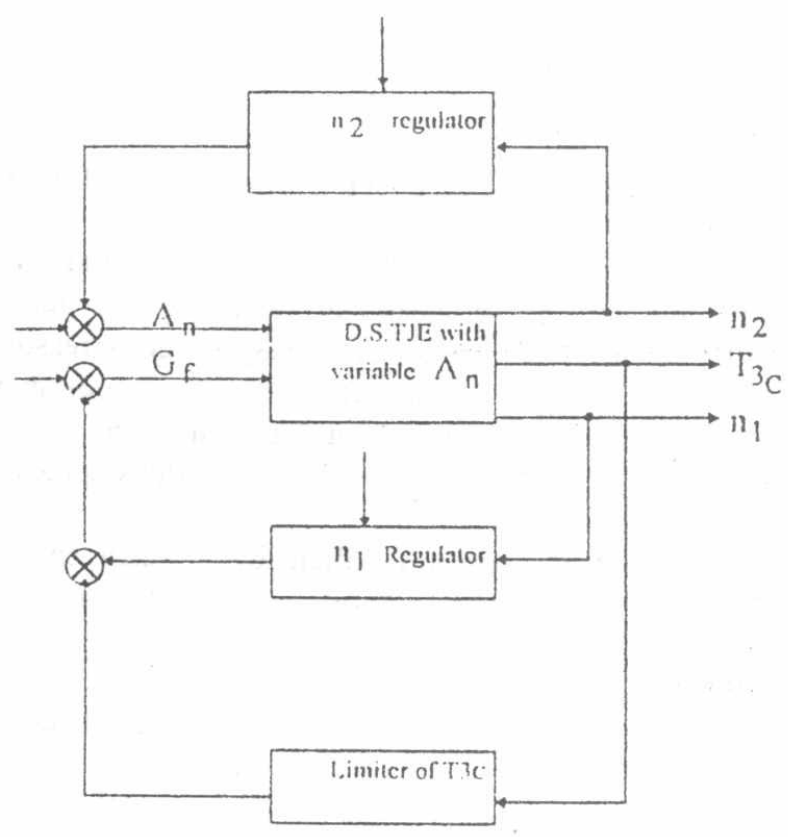

Figure 1. Block scheme of the studied double spool turbojet engine regulation system

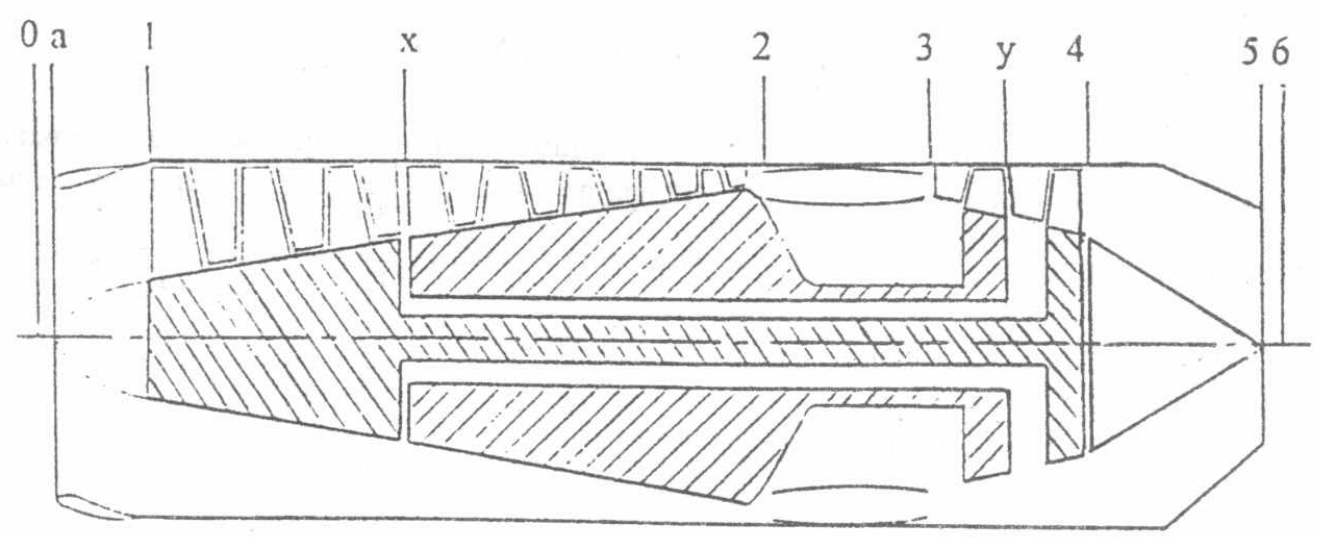

Figure 2. Simplified scheme of double spool turbojet engine 


\section{4- CONSTRUCTION OF THE HIGH PRESSURE COMPRESSOR MAP}

As the engine components are given by their maps then it is important to get the engine component characteristics in order to enable the analysis and modeling of this engine. When dealing with the acceleration problem of the engine. It is important to predict the characteristics of the engine compressors

The compressor characteristics are given by

$$
\text { r } \begin{aligned}
\Pi_{\mathbf{k}_{c}} & =\Pi_{\mathrm{k}_{c}}\left(\frac{\mathrm{m} \sqrt{\mathrm{T}_{1_{c}}}}{\mathrm{P}_{1_{c}}}, \frac{\mathrm{n}}{\sqrt{\mathrm{T}_{1_{c}}}}\right) \\
\text { and } \quad \eta_{\mathbf{k}_{c}} & =\eta_{\mathrm{k}_{c}}\left(\frac{\mathrm{m} \sqrt{\mathrm{T}_{\mathrm{l}_{c}}}}{\mathrm{P}_{\mathrm{l}_{c}}}, \frac{\mathrm{n}}{\sqrt{\mathrm{T}_{c_{c}}}}\right)
\end{aligned}
$$

Where the compressor efficiency $\eta_{k}$ is given by ;

$$
\eta_{k_{c}}=\frac{L_{a d k}}{L_{c}}=\frac{C_{p} T_{l_{c}}\left(\Pi_{k_{c}}((K-1) / K)-1\right)}{L_{c}}
$$

\subsection{Determination of the High Pressure Compressor Characteristics}

The compressor characteristics of the studied engine are obtained by using the simplified method [6]. This method provides a means of obtaining the performance map of a new compressor from the results of previously designed compressor. It is based upon the correlation of data from several compressors, so it is possible to obtain a complete performance map from known compressor design conditions. There are three phases of the calculation procedure such that the integration of these phases results in a complete compressor performance map

1- Calculation of the points of maximum efficiency at each speed. The line of maximuin efficiency is called the backbone of compressor map, and the values along this line are termed backbone values

2- Determination of the stall- limit line. The values along this line are referred to as stall limit values

3- Calculation of the points along the constant speed lines from stall limit to maximum flow

The high pressure compressor characteristics of the studied engine are calculated by Shafiek [9] and the results are plotted in Fig. 3.

\subsection{Determination of the Curves of Common Work}

The curves of common work are the curves drawn in the compressor characteristics and representing the common work of all engine parts. They are obtained by using the Approximate method, [7], which gives good results for of $\left(\frac{\mathrm{n}_{1}}{\sqrt{\mathrm{T}_{\mathrm{x}_{\mathrm{c}}}}}\right) \geq 0.6\left(\frac{\mathrm{n}_{1}}{\sqrt{\mathrm{T}_{\mathrm{x}_{c}}}}\right)_{\max }$. 


\section{Assumptions;}

1- At the design conditions and around it , $\left(\frac{\mathrm{n}_{1}}{\sqrt{\mathrm{T}_{\mathrm{x}_{\mathrm{c}}}}}\right) \geq 0.6\left(\frac{\mathrm{n}_{1}}{\sqrt{\mathrm{T}_{\mathrm{x}_{\mathrm{c}}}}}\right)_{\max }$, the turbine is choked.

$$
\left(\frac{m \sqrt{T_{3_{c}}}}{P_{3_{c}}}\right)=\left(\frac{m \sqrt{T_{3_{c}}}}{P_{3_{c}}}\right)_{d}=\text { constant }
$$

2- The operating regime in the combustion chamber changes a little. i.e. the coefficient of conservation of total pressure in combustion chamber can be considered constant .

$$
\sigma_{\mathrm{cc}}=\text { constant }
$$

\section{Calculation Procedure;}

1- From the high pressure compressor characteristics, A value of $\left(\frac{n_{1}}{\sqrt{T_{x_{c}}}}\right)$ is selected and the corresponding values of $\left(\frac{\mathrm{m} \sqrt{\mathrm{T}_{\mathrm{x}_{\mathrm{c}}}}}{\mathrm{P}_{\mathrm{x}_{\mathrm{C}}}}\right)$ is determined.

2- For several values of $\left(\frac{T_{3 c}}{T_{x_{c}}}\right)$, calculate $\Pi_{k_{c}}$ such that ;

$$
\Pi_{k_{c}}=\frac{1}{\left(\frac{m \sqrt{T_{3_{c}}}}{P_{3_{c}}}\right)_{d}} \frac{1}{\sigma_{c c}}\left(\frac{m \sqrt{T_{x_{c}}}}{P_{x_{c}}}\right) \sqrt{\frac{T_{3_{c}}}{T_{x_{c}}}}
$$

This equation represent a straight line passing through the origin for each value of $\left(\frac{T_{3_{c}}}{T_{x_{c}}}\right)$. The previous steps are repeated for several values of $\left(\frac{n_{1}}{\sqrt{T_{x_{c}}}}\right)$ and the results are calculated by Shafiek [9] and plotted in Fig. 4

\subsection{Determination of the Equilibrium Run of High Pressure Rotor}

The conditions of work of high pressure rotor in case of double spool turbojet engine correspond fully to the conditions of work of single spool turbojet engine. Therefore, it is found better to determine the equilibrium run of high pressure rotor on the supposition that the characteristics of the high pressure compressor are known. [7]

\section{Assumptions}

For the basic regimes of work, The high and low pressure turbines are choked then;

$$
\begin{aligned}
& \left(\frac{m \sqrt{T_{3 c}}}{P_{3_{c}}}\right)=\left(\frac{m \sqrt{T_{3_{c}}}}{P_{3_{c}}}\right)_{d}=\text { constant } \\
& \left(\frac{m \sqrt{T_{y_{c}}}}{P_{y_{c}}}\right)=\left(\frac{m \sqrt{T_{y_{c}}}}{P_{y_{c}}}\right)_{d}=\text { constant }
\end{aligned}
$$


From which it is valid that:

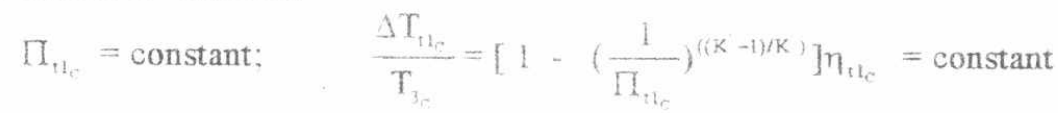

where $\frac{\Delta T_{11_{c}}}{T_{3 e}}=\frac{C_{p}}{C_{p}} \frac{1}{\eta_{m}} \frac{\Delta T_{k i}}{T_{3 e}}$

Then

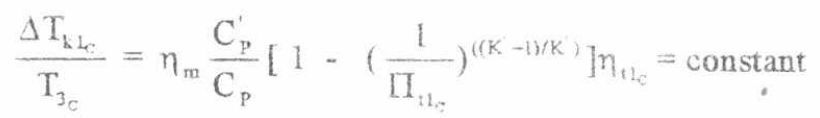

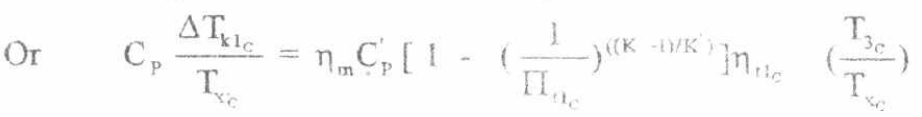

\section{Calculation procedure;}

1-For arbitrary value of $\left(\frac{\mathrm{n}_{1}}{\sqrt{\mathrm{T}_{\mathrm{x}_{\mathrm{c}}}}}\right)$ in the compressor characteristics, A values of $\left(\frac{\mathrm{T}_{3 \mathrm{c}}}{\mathrm{T}_{\mathrm{x}_{\mathrm{c}}}}\right)_{\text {est }}$ aI estimated and then for these values calculate;

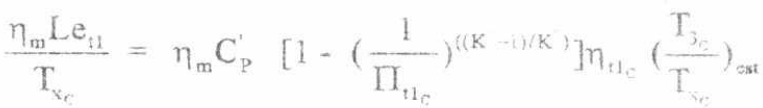

2- For the same value of $\left(\frac{a_{1}}{\sqrt{T_{w}}}\right)$ and from the compressor characteristics read the values of $\left(\frac{\mathrm{m} \sqrt{\mathrm{T}_{\mathrm{x}_{\mathrm{c}}}}}{\mathrm{P}_{\mathrm{x}_{\mathrm{c}}}}\right), \Pi_{\mathrm{k} L_{\mathrm{c}}}, \frac{\Delta \mathrm{T}_{\mathrm{k}_{\mathrm{c}}}}{\mathrm{T}_{\mathrm{x}_{\mathrm{c}}}}$.

3- The mass flow rate through the turbine can be written in the form

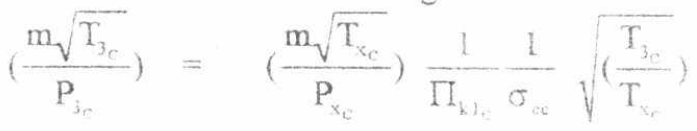

For choked turbine, calculate $\left(\Pi_{k_{1},}\right)_{c a i}$ for the estimated values of $\left(\frac{T_{3 c}}{T_{\mathrm{x}_{c}}}\right)_{\text {est }}$

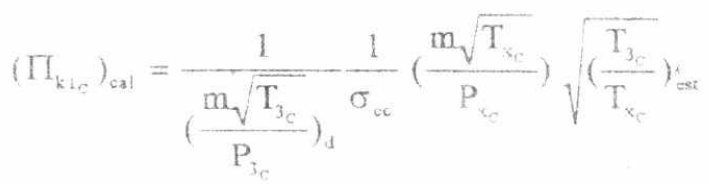

4- The value of $\Pi_{\mathrm{k}_{\mathrm{c}}}$ read from the compressor characteristics and the calculated value $\left(\Pi_{\mathrm{k}_{\mathrm{c}}}\right)_{\mathrm{cal}}$ are compared for each estimated value of $\left(\frac{\mathrm{T}_{3_{\mathrm{c}}}}{\mathrm{T}_{\mathrm{x}}}\right)_{\mathrm{cst}}$ such that $\Delta=\left(\Pi_{\mathrm{k} \mathrm{l}_{\mathrm{c}}}\right)_{\mathrm{cal}}-\Pi_{\mathrm{k} 1_{\mathrm{e}}}$

For $\Delta=0$, the corresponding value of $\frac{\Delta T_{k p_{r}}}{T_{k_{c}}}$ is determined. 
5- For each determined value of $\frac{\Delta T_{k_{1}}}{T_{x_{c}}}$ from the previous step, calculate $L e_{k 1}$ such that:

$\mathrm{Le}_{\mathrm{k} 1}=\mathrm{C}_{\mathrm{P}} \frac{\Delta \mathrm{T}_{\mathrm{kt}_{\mathrm{C}}}}{\mathrm{T}_{\mathrm{x}_{\mathrm{c}}}}$

For the point of equilibrium run, the results from step 1 and 6 should agree and the results are calculated by Shafiek [9] and plotted in Fig. 4.

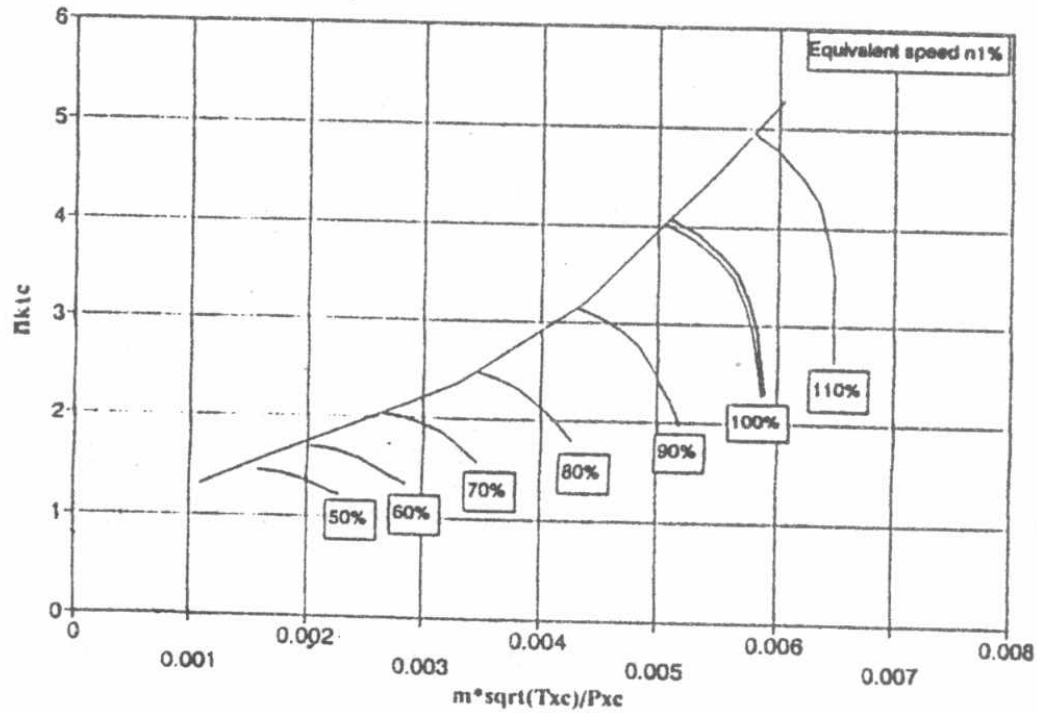

Fig. 3 The high pressure compressor characteristics

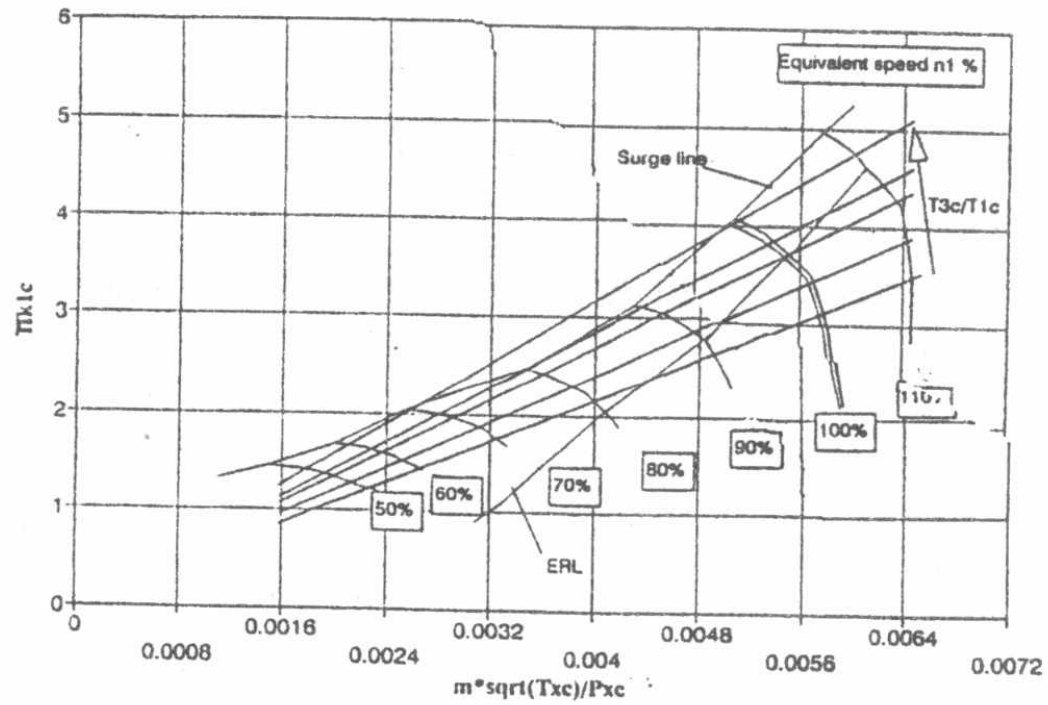

Fig. 4 The high pressure compressor map 


\section{5- DETERMINATION OF THE ACCELERATION TIME}

In the region of the hydraulic retarder operation from $\mathrm{n}_{1}=80 \%$ to $\mathrm{n}_{1}=\mathrm{n}_{\max }$ the acceleration time could be determined from the compressor map as follows;

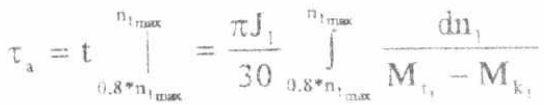

where

$$
\begin{aligned}
& \left.M_{k 1}=\frac{30 m C_{p} T_{x_{c}}}{\pi n_{1} \eta_{k t_{c}}}\left(\Pi_{k t_{c}}(\mathrm{~K}-1) / k\right)-1\right) \\
& \text { and } \quad \mathrm{M}_{\mathrm{t}}=\frac{30 \mathrm{mC}_{\mathrm{p}}^{\prime} \mathrm{T}_{3 \mathrm{c}}}{\pi \mathrm{n}_{1}}\left(1-\Pi_{\mathrm{t} \mathrm{1}_{\mathrm{c}}}^{(1-\mathrm{k}) / \mathrm{K})}\right) \eta_{\mathrm{ur}}
\end{aligned}
$$

The calculation of this integration could be carried out according to the following procedure :

(1) Choose an acceleration path on the high pressure compressor map

(2) For the chosen acceleration path, the parameters $m, \Pi_{k L_{c}}, T_{x_{r}}, \eta_{k 1_{c}}$ are determined for preselected values of $n_{1}$ in the region $0.8 n_{l_{\max }} \leq n_{1} \leq n_{l_{\max }}$ and calculate the corresponding value of $\mathrm{M}_{\mathrm{x} 1}$.

(3) For the same acceleration path, the parameters $m, \Pi_{t i_{c}}, T_{3_{c}}, \eta_{t l_{c}}$ are determined for the selected values of $n_{1}$ in the region $0.8 n_{n_{\max }} \leq n_{1} \leq n_{1_{\max }}$ and calculate the corresponding values of $\mathrm{M}_{11}$.

(4) At each selected value of $\mathrm{u}_{1}$, a corresponding value of $\Delta \mathrm{M}_{\mathrm{tk} l}=\mathrm{M}_{\mathrm{t} 1}-\mathrm{M}_{\mathrm{k} 1}$ is determined then. plot the $\left[1 /\left(\mathrm{M}_{\mathrm{t1}}-\mathrm{M}_{\mathrm{b}, 1}\right)\right]-\mathrm{n}_{1}$ relation.

(5) calculate $\tau_{3}=\left.t\right|_{\frac{n_{1}}{n_{1}}}=\frac{\pi J_{1}}{30}[$ area under the curve $]$

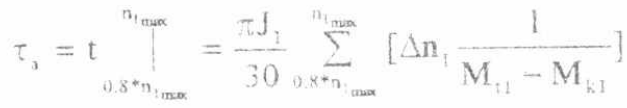

\section{6-MODELING OF THE HYDRACLIC RETARDER}

Considering the principle scheme of the hydraulic retarder, Fig. 5, the following mathematica model could be deduced, neglecting the internal leakage and assuming constant fue temperature.

$$
Q_{\omega 0}=C_{i \omega} A_{T \omega} \sqrt{\frac{2}{\rho}\left(p_{\omega}-p_{0}\right)}
$$




$$
\begin{aligned}
& Q_{i}=C_{d i} A_{r i} \sqrt{\frac{2}{\rho}\left(p_{\omega}-p_{i}\right)} \\
& Q_{i i}=C_{d i i} A_{r i i} \sqrt{\frac{2}{\rho}\left(p_{i}-p_{i i}\right)} \\
& Q_{i i i}=C_{d i i i} A_{r i i j}(z) \sqrt{\frac{2}{\rho} p_{i i}} \\
& Q_{\omega}-Q_{i}-\frac{V_{\omega}}{B} \frac{d p_{\omega}}{d t}=0 \\
& Q_{i}-Q_{i i}-A_{p} \frac{d y}{d t}-\frac{V_{i}+A_{p} y}{B} \frac{d p_{i}}{d t}=0 \\
& Q_{i i}-Q_{i i i}-\frac{V_{i i j}}{B} \frac{d p_{i i}}{d t}=0 \\
& p_{i} A_{p}=m_{r d} \frac{d^{2} y}{d t^{2}}+f \frac{d y}{d t}+k_{e q} y
\end{aligned}
$$

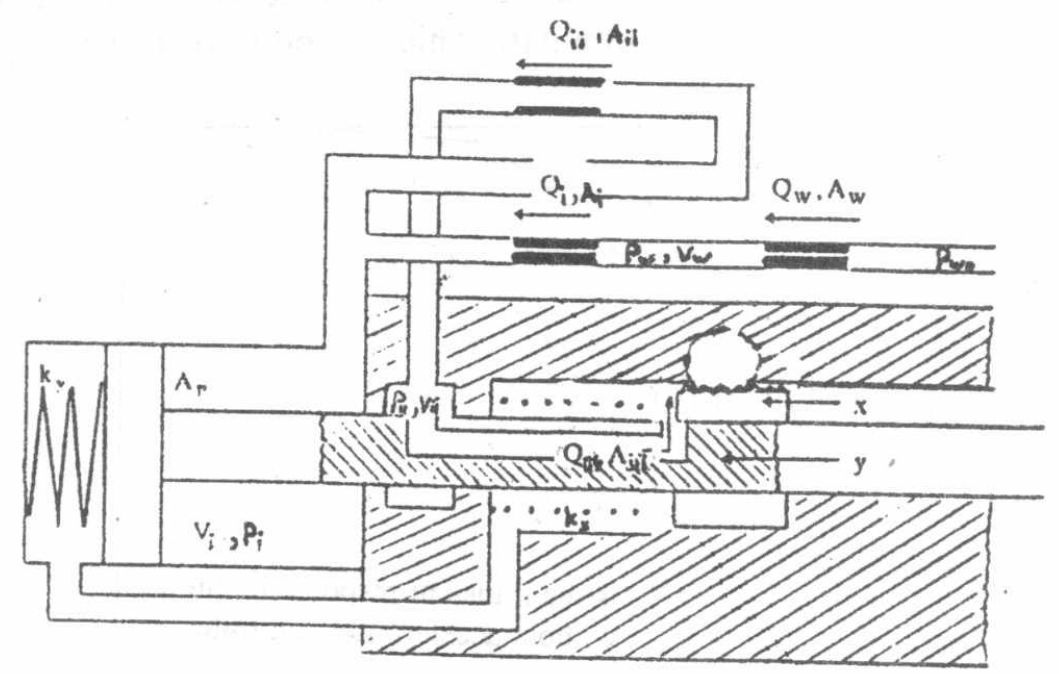

Fig. 5 Principle scheme of hydraulic retarder

The throttling area of the orifice $\mathrm{A}_{\mathrm{iii}}(\mathrm{z})$ could be calculated by the following expression (where The orifice radius $\mathrm{r}=0.45 \mathrm{~mm}$ ) :

$$
A_{\text {iii }}(z)=\begin{array}{ll}
r^{2} \cos ^{-1}\left[\frac{r-z}{r}-(r-z) \sqrt{\left(2 r z-z^{2}\right)}\right. & \text { for } \quad z \leq 0 \\
\pi r^{2}-\left\{r^{2} \cos ^{-1}\left[\frac{r-z}{r}-(r-z) \sqrt{\left(2 r z-z^{2}\right)}\right]\right. & \text { for } 0<z \leq r \\
\pi r^{2} & \text { for } r \leq z \leq 2 r
\end{array}
$$

TUTSIM simulation program [8] is used to predict the system behavior when the gate valve displacement changes and to find the effect of constructional and operational parameters on the system performance.. 


\section{7- ANALYSIS OF RESULTS}

Different acceleration paths, drawn in the high pressure compressor map, were selected and the corresponding acceleration time was evaluated for each path. The acceleration time, when accelerating the engine from $\overline{\mathrm{n}}=0.8$ to 1 in the region of operation of the hydraulic retarder, given by the manufacturer should be in the range from 2.5 to 4.5 seconds. The tests on the engine test bed give an acceleration time of 3.4 seconds. $\left(\vec{n}=n . / n_{\max }\right)$

Figure 6 , shows the corresponding acceleration characteristics for three of the pre-selected acceleration paths. These acceleration paths were selected, such that, the first one is too near to the surge line and gives an acceleration time just less than the minimum value of the recommended range given by the manufacturer, the third is too near to the equilibrium run line and gives the maximum acceleration time of the recommended range given by the manufacturer, and the second is one of the intermediate paths. The figure carries also the engine transient response of the studied engine to step increase in fuel. The engine step response was predicted on the basis of the transfer function (5). The study of this figure shows that the acceleration characteristics of the engine, without an automatic acceleration device, could not be accepted. The engine transient response is toofast even with respect to the acceleration characteristics of the first acceleration path which is too near to the surge line.

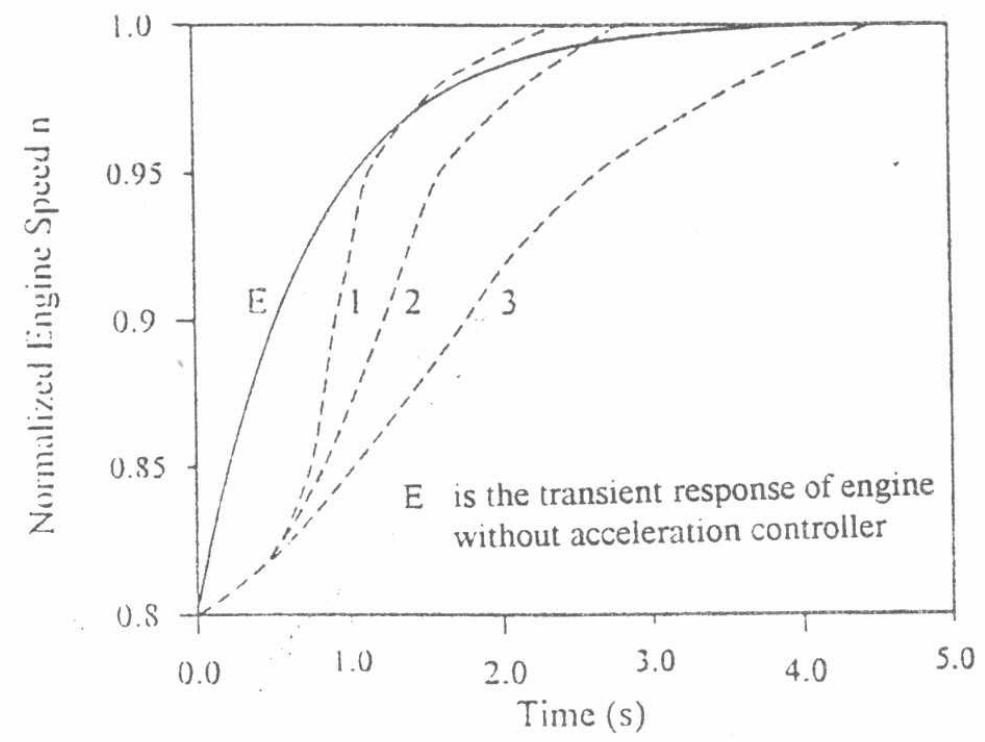

Figure 6. The engine transient response to step increase in fuel $\Delta \overline{\mathrm{G}}_{\mathrm{f}}$ with the required $\bar{n}(t)$ relation for the three selected acceleration paths

Figure 7 , shows the transient response of the hydraulic retarder to a step displacement $x$ of magnitude $1 \mathrm{~mm}$. The study of this figure shows that before the application of the step application in $\mathrm{x}$, all of the parameters are constant. The step displacement $\mathrm{x}$ is applied at

$t=0.5 \mathrm{~s}$ The throttle area $A_{i i j}$ closes and the fuel flow $Q_{i i}$ becomes zero and the pressures $p_{i} \& p_{i i}$ are equal. The fuel flows from the high pressure line of constant pressure $p_{\omega_{0}}$ to the servopiston chamber. The flow rate, and consequently the piston speed, are dictated by the two inlet restrictions. [Generally, the behavior of the hydraulic retarder is very sensitive to the variation of the inlet restriction areas. The increase in the inlet restriction areas may lead to 
excessive pressure in the servopiston chamber. In this case, the piston displaces continuously to its end position, and the hydraulic retarder is blocked]. The piston displaces, and the exit restriction area starts to open until reaching a new steady state position.

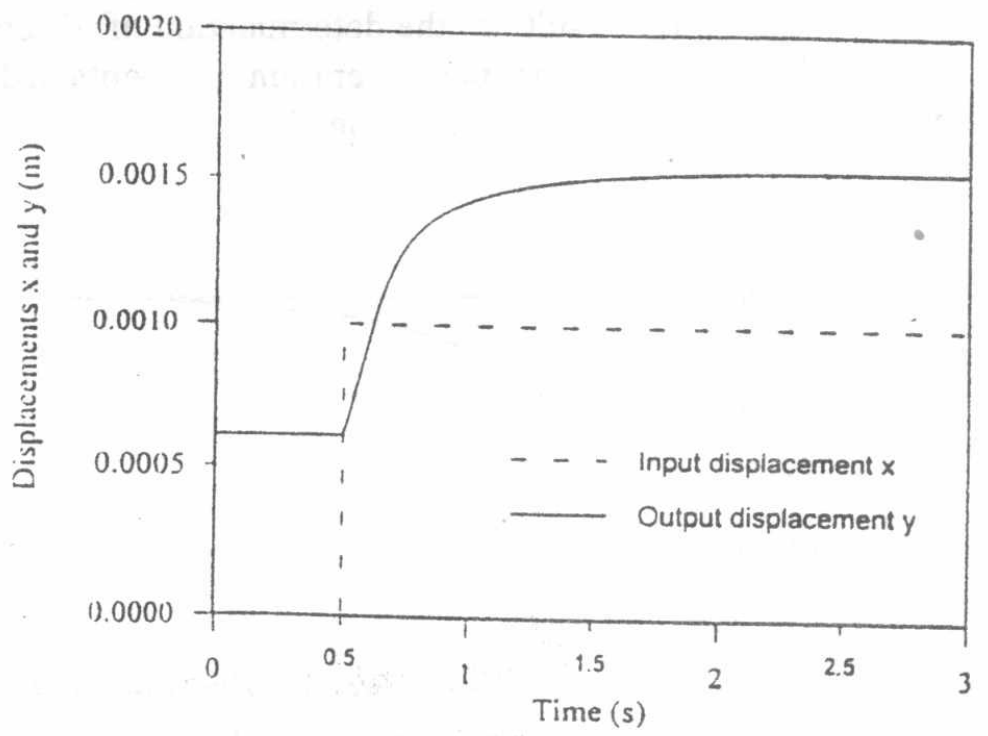

Figure 7. Transient response of piston rod displacement y to step increase of gate valve displacement $\mathrm{x}$ from 0 to $0.001 \mathrm{~m}$ applied at $\mathrm{t}=0.5 \mathrm{~s}$

As shown in Fig. 7, the used hydraulic retarder presents a transient response of 0.9 seconds. From the experience, on similar variable displacement pumps, the fuel pump settling time is less than 0.1 seconds. Therefore, in this study, the dynamics of the pump could be neglected with respect to the hydraulic retarder, and the engine control system could be represented by the following block diagram, Fig 8.

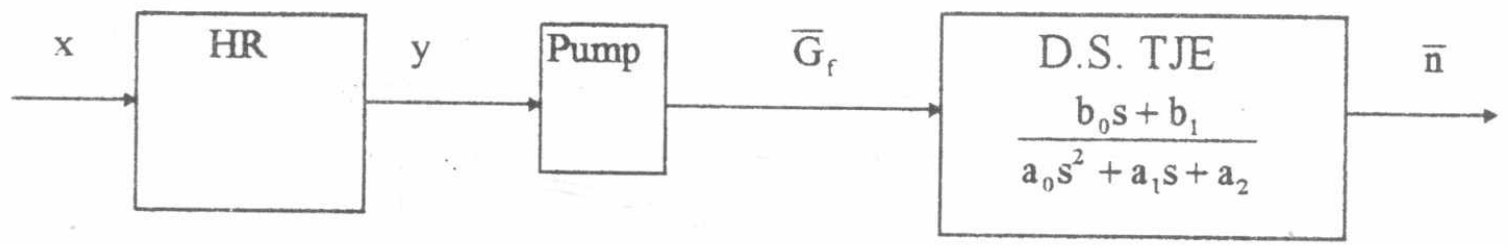

Fig. 8 Block diagram of the studied engine equipped with hydraulic retarder

The acceleration characteristics of the engine, equipped with hydraulic retarder, are evaluated by using TUTSIM simulation program. The results are given in Figures $9,10,11$. The study of these figures shows that the required $\bar{n}(\mathrm{t})$ relation which corresponds to the acceleration paths $2 \& 3$, fig. 10,11, could be reached with acceptable precision by slight tuning of the hydraulic retarder constructional parameters. These parameters are the diameters of the throttling orifices, the spring stiffness and the piston area. The required $\bar{n}(t)$ relation which corresponds to the acceleration path 1, Fig. 9, is not acceptable. During the experimentation on the simulation program, no corresponding acceleration characteristics could be obtained for the studied hydraulic retarder. This result is of special importance. It shows that the used hydraulic retarder does not produce any acceleration path touching the surge line even with considerable 
wear in its elements for the case that the pilot changes the throttle lever displacement to accelerate the engine from one thrust level to another in the region of operation of the hydraulic retarder. Another important result is the determination of the nearest acceleration path to the surge line which gives the minimum acceleration time, obtained by the developed model, and has acceptable acceleration characteristics, Fig. 10.

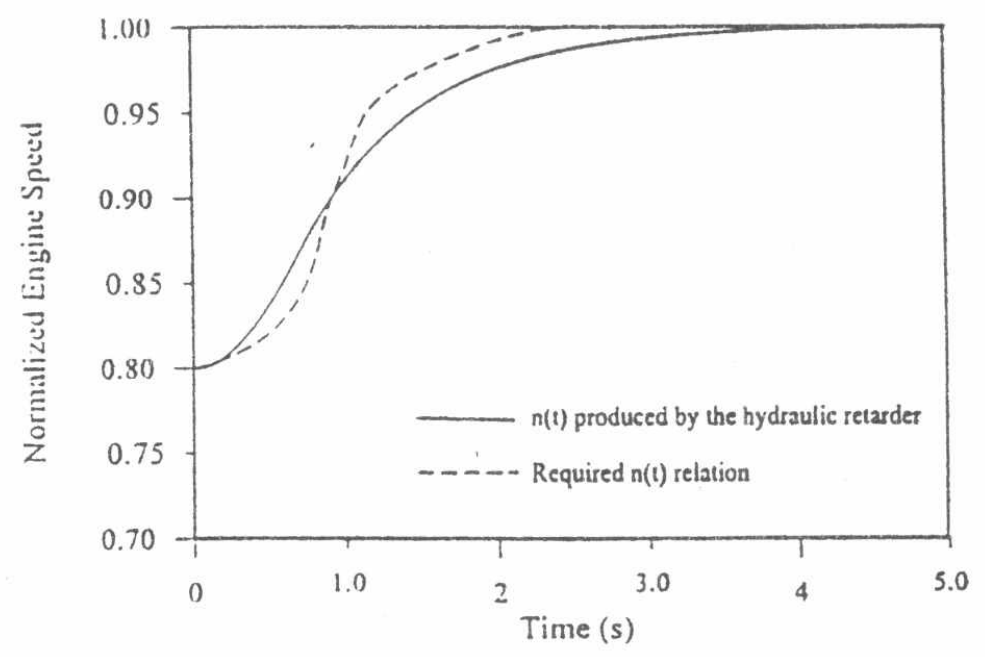

Figure 9 Comparison between the required $\bar{n}(t)$ relation and the one produced by hydraulic retarder for acceleration line case (1)

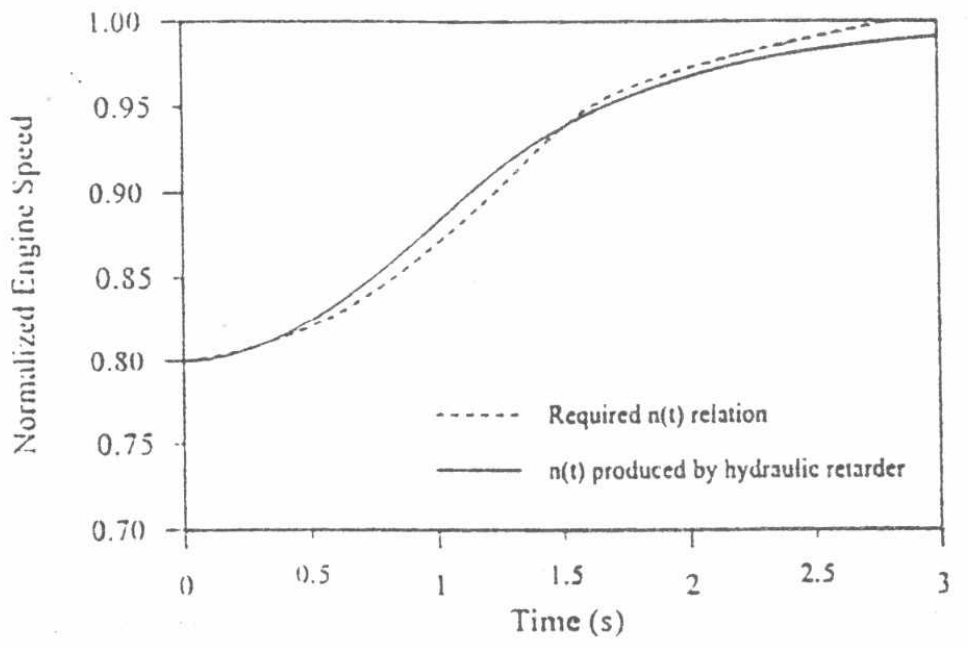

Figure 10 Comparison between the required $\overline{\mathrm{n}}(\mathrm{t})$ relation and the one produced by hydraulic retarder for acceleration line case (2) 


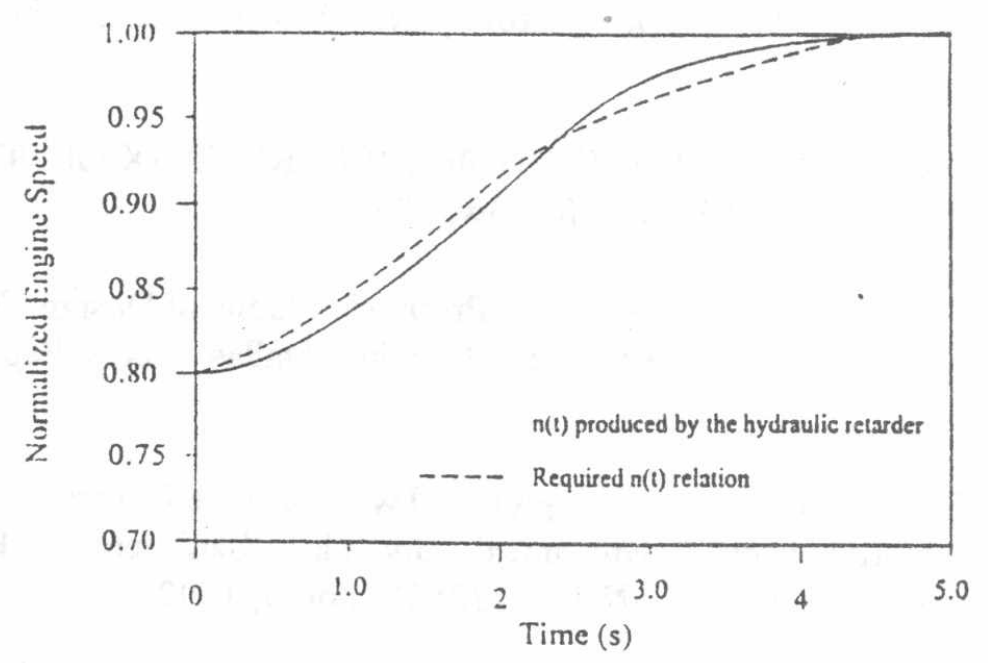

Figure 11 Comparison between the required $\bar{n}(t)$ relation and the one produced by hydraulic retarder for acceleration line case (3)

\section{8- CONCLUSION}

In this paper, the static and dynamic characteristics of a double spool turbojet engine as well as the effect of using a hydraulic retarder as an automatic acceleration device on the engine acceleration characteristics were investigated. The following conclusions could be reached :

1- The studied engine presents a non acceptable acceleration characteristics without using an acceleration control device.

2- The implementation of a hydraulic retarder improved the acceleration characteristics of the engine.

3- By proper tuning of the hydraulic retarder constructional parameters, the recommended engine acceleration path could be reproduced, and the engine presented an acceleration time corresponding to the recommended range given by the manufacturer.

4- The minimum acceleration time is obtained by the developed model and the corresponding acceleration path which has acceptable acceleration characteristics is determined.

5- In this case of study, the actual design of the studied hydraulic retarder does not produce any acceleration path touching the surge line, even with considerable wear in its elements. 


\section{9- REFERENCES}

[1] D' Azzo, J.J. and Houpis, C.H., 'Feedback Control System Analysis and Synthesis', McGrow Hill Co., New York, 1960.

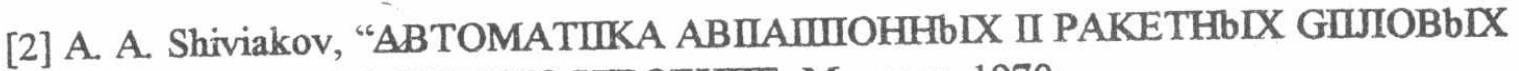
YCTAHOBOK”, MAIIIIHOCTPOEHUE, Moscow, 1970.

[3]G. T. Sevich and E. C. Beattie, "Integrated Flight / Propulsion Control Design Techniques Starting with the Engine", SAE Air Transportation Meeting, Dallas, Taxas, Paper 74-0481 Apr. 30-May 2, 1974.

[4] J. Thang, K. Hua, Y. Guo, and F. Liu, "A Design of a Twin Variable Control System for Aero-Turbojet Engine", Northwestern Polytechnical University, Xian, People's Republic of China, Journal of Aerospace Power (ISSN 1000-8055), Vol. 5, 1990.

[5] El-Mayah, M.T., "Gas Turbine Engine Analysis and Control", The Ohio State University, Dept. of Aeronautical Engineering, AAE-694, 1982.

[6]William H. Robbins and James F. Dugan, "Prediction of Off-design Performance of multistage Compressors", NASA SP-36, 1965.

[7] El-Zahaby, A. A. "Theoretical Prediction of Double Spool Turbojet Engine Flight Performance", Military Technical College, Department of Mechanical Engineering, 1993.

8] "TUTSIM on IBM Computers, Users Manual, Version 7", Meerman Automation, The Netherlands, 1990.

9]Shafiek,A., "Controlling the Acceleration of Double Spool Turbojet Engine of unknown Compressor Map by using a Hydraulic Retarder", M. Sc. Thesis, Military Technical College, Department of Mechanical Engineering, 1996.

\section{0-APPENDIX}

From the principle scheme of double spool turbojet engine, assuming constant surrounding conditions. The following mathematical model of could be developed .

$$
\begin{aligned}
& 2 \pi \mathrm{J}_{1} \frac{\mathrm{dn}_{1}}{\mathrm{dt}}=\mathrm{M}_{\mathrm{t} 1}-\mathrm{M}_{\mathrm{k} 1} \quad ; \quad 2 \pi \mathrm{J}_{2} \frac{\mathrm{dn_{2 }}}{\mathrm{dt}}=\mathbf{M}_{\mathrm{t} 2}-\mathbf{M}_{\mathrm{k} 2}
\end{aligned}
$$

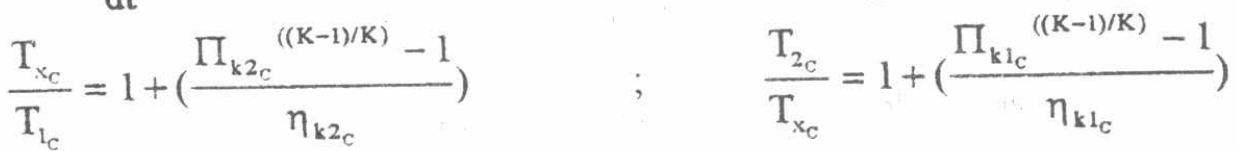

$$
\begin{aligned}
& \mathrm{m}_{\mathrm{k} 2}=\mathrm{m}_{\mathrm{k} 1} \quad ; \quad \mathrm{m}_{\mathrm{k} 1}=\mathrm{m}_{\mathrm{t} 1}
\end{aligned}
$$

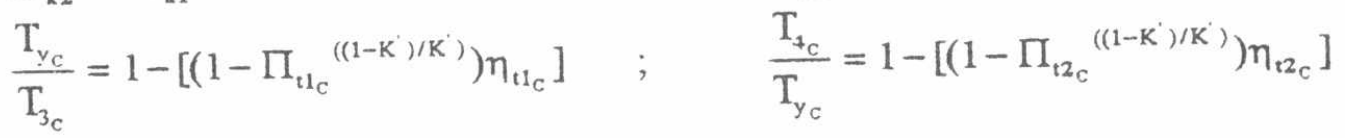

$$
\begin{aligned}
& \mathrm{m}_{\mathrm{t} 1}=\mathrm{m}_{\mathrm{t} 2} \quad ; \quad \mathrm{m}_{\mathrm{t} 2}=\mathrm{m}_{\mathrm{n}}
\end{aligned}
$$




$$
\mathrm{G}_{\mathrm{f}} \mathrm{Hu}_{\mathrm{co}}=\mathrm{m}_{\mathrm{k}}\left[\left(\mathrm{C}_{\mathrm{p}}^{\prime} \mathrm{T}_{3_{\mathrm{c}}}\right)-\left(\mathrm{C}_{\mathrm{p}} \mathrm{T}_{\mathrm{2}_{\mathrm{c}}}\right)\right]
$$

The parameters included in the previous system of equations could be expressed as follows:

$$
\begin{aligned}
& M_{\mathrm{t} 1}=\mathbf{M}_{\mathrm{t} 1}\left(\mathrm{~T}_{\mathrm{B}_{\mathrm{c}}}, \mathrm{m}_{\mathrm{t} 1}, \mathrm{n}_{1}, \Pi_{\mathrm{t}_{\mathrm{c}}}\right) \\
& M_{t 2}=M_{t 2}\left(T_{y_{c}}, m_{t 2}, n_{2}, \Pi_{t_{2}}\right) \\
& M_{k 1}=M_{k 1}\left(m_{k 1}, n_{1}, \Pi_{k 1}, T_{x_{c}}, P_{x_{c}}\right) \\
& M_{\mathrm{k} 2}=\mathbf{M}_{\mathrm{k} 2}\left(\mathrm{~m}_{\mathrm{k} 2}, \mathrm{n}_{2}, \Pi_{\mathrm{k} 2 \mathrm{c}}, \mathrm{T}_{1_{\mathrm{c}}}, \mathrm{P}_{1_{\mathrm{c}}}\right) \\
& \mathrm{m}_{\mathrm{k} 1}=\mathrm{m}_{\mathrm{k} 1}\left(\mathrm{n}_{1}, \Pi_{\mathrm{k}_{\mathrm{c}}}, \mathrm{T}_{\mathrm{x}_{\mathrm{c}}}, \mathrm{P}_{\mathrm{x}_{\mathrm{c}}}\right) \\
& \mathrm{m}_{\mathrm{k} 2}=\mathrm{m}_{\mathrm{k} 2}\left(\mathrm{n}_{2}, \Pi_{\mathrm{k} 2_{\mathrm{c}}}, \mathrm{T}_{\mathrm{l}_{\mathrm{c}}}, \mathrm{P}_{\mathrm{t}_{\mathrm{c}}}\right) \\
& \mathrm{m}_{\mathrm{t} 1}=\mathrm{m}_{\mathrm{t} 1}\left(\mathrm{P}_{3_{\mathrm{c}}}, \mathrm{T}_{3_{\mathrm{c}}}\right) \\
& \mathrm{m}_{\mathrm{t} 2}=\mathrm{m}_{\mathrm{t} 2}\left(\mathrm{P}_{\mathrm{y}_{\mathrm{c}}}, \mathrm{T}_{\mathrm{y}_{\mathrm{c}}}\right) \\
& \mathrm{m}_{\mathrm{n}}=\mathrm{m}_{\mathrm{n}}\left(\mathrm{P}_{4_{\mathrm{C}}}, \mathrm{T}_{4_{\mathrm{c}}}, \mathrm{A}_{\mathrm{n}}\right) \\
& \Pi_{\mathbf{k} 2_{c}}=\frac{\mathbf{P}_{\mathrm{x}_{\mathrm{c}}}}{\mathbf{P}_{1_{\mathrm{c}}}} \quad ; \quad \Pi_{\mathbf{k}_{1} \mathrm{c}}=\frac{\mathbf{P}_{2_{c}}}{\mathbf{P}_{\mathrm{x}_{\mathrm{c}}}} \\
& \Pi_{t_{1}}=\frac{\mathbf{P}_{3_{c}}}{\mathbf{P}_{\mathrm{y}_{\mathrm{c}}}} \quad ; \quad \Pi_{t_{2}}=\frac{\mathbf{P}_{\mathrm{y}_{\mathrm{c}}}}{\mathbf{P}_{4_{\mathrm{c}}}} \\
& P_{3_{c}}=\sigma_{c c} P_{2_{c}}
\end{aligned}
$$

